\title{
ANÁLISE DA APLICABILIDADE DE SISTEMAS DE MOVIMENTAÇÃO E ARMAZENAMENTO DE MATERIAIS NO SETOR ATACADISTA: UM ESTUDO DE CASO NA
} EMPRESA CEALTA.

\author{
ANALYSIS DRIVE SYSTEMS OF APPLICATION AND MATERIALS \\ STORAGE IN WHOLESALE SECTOR: A CASE STUDY IN THE COMPANY \\ CEALTA.
}

FELIX ${ }^{1}$ Edgar da Silva; NUNES, Maria das Graças C.; SAMPAIO, Joabe Vieira; GALVÃO FILHO, Demócrito.

Recebido em: 15/09/2017; Aceito: 20/11/2017; Publicado: 01/12/2017.

\section{RESUMO}

A presente pesquisa tem por fim agregar conhecimento ao âmbito acadêmico e social por meio da análise de um estudo de caso sobre a aplicabilidade dos sistemas e técnicas provenientes da logística de movimentação e armazenagem de estoque e suas possíveis vantagens. Através de um estudo de caso, buscou-se conhecer todo o processo de entrada e saída de materiais, as técnicas e equipamentos utilizados para movimentação e armazenagem de materiais e o processo de separação de produtos. Analisou-se, portanto o sistema utilizado pela CEALTA, empresa do setor alimentício em Juazeiro do Norte - CE que possibilitou a visualização e a concretude das vantagens oferecidas pela utilização do sistema tais como a optimização do espaço e tempo de entrada e saída de materiais, zero de número de acidentes de trabalho, avarias próximo de zero etc.

PALAVRAS-CHAVE: Armazenamento, estocagem, movimentação, Materiais, Empresa.

\section{ABSTRACT}

This research aims to add knowledge to the academic and social context by analyzing a case study on the applicability of the systems and techniques from the logistics of moving and storing stock and its possible advantages. Through a case study, we sought to understand the entire process of incoming and outgoing materials, techniques and equipment used for handling and storage of materials and the process of separation of products. We analyzed therefore the system used by CEALTA, company in the food sector in Juazeiro do Norte - CE allowed the visualization and the concreteness of the advantages offered by the use of the system such as the optimization of space and time of entry and exit of materials, zero number of accidents, breakdowns near zero etc.

KEYWORDS: Storage, inventory, handling, materials, Company.

\footnotetext{
${ }^{1}$ Rua Odete Matos de Alencar, N 2605, Lagoa Seca, Juazeiro do Norte- CE. E-mail: edgarsfelix@gmail.com; Tel. 9288-9500.
} 


\section{INTRODUÇÃO}

Com a globalização surgiram diversas oportunidades e desafios. O avanço tecnológico teve sua parcela de contribuição acima de tudo para um sobresalto no processo de inovação dentro das organizações.

Outro grande desafio é a competitividade, que traz consigo a obrigatoriedade de melhoria continua da qualidade dos produtos e serviços oferecidos, bem como, com a constante preocupação com a redução dos custos a fim de atender as necessidades e desejos dos consumidores.

Atualmente há um crescimento contínuo na busca de aperfeiçoamento, o que impõe aos gestores manterem-se sempre informados e, sobretudo dispostos a aplicar inovações em sua administração.

Para a solução de tais dificuldades os gestores contam com a ajuda da logística que oferece uma ferramenta para uma gestão eficaz de materiais, nota-se sua importância através da análise descrita por Gonçalves (2010) afirmando que os materiais correspondem mais de $50 \%$ do capital empregado pela empresa.

Inicialmente se utilizou de uma pesquisa bibliográfica e posteriormente um estudo de caso, onde se investigou a aplicabilidade das técnicas e equipamentos utilizados na movimentação e armazenagem de materiais e suas possíveis contribuições. A pesquisa é classificada como qualitativa, exploratório-descritiva, não probabilística, com dados primários e secundários, aplicada por meio de uma entrevista ao gestor de logística da empresa CEALTA.

\section{ARMAZENAGEM DE MATERIAIS}

As empresas necessitam de estocagem de produtos e movimentação de materiais por não ter uma exatidão de sua demanda e por não suprir essa demanda de forma instantânea, em contraste não haveria motivos para tal prática. (BALLOU, 2010)

Dias (2010) assegura que os esforços gastos para estocar e movimentar matéria-prima, produtos semiacabados ou até mesmo os produtos acabados são compensados na melhoria da qualidade dos produtos, na redução dos custos de operações e na agilidade com a qual são realizados os trabalhos.

Os custos também podem diminuir pela compensação de gastos de transportes e compra de produção fazendo uso do lote econômico de compra. Um transporte de quantidade maiores, mais econômico e evitando as flutuações de níveis de produção e variações de demanda, sempre buscando o controle de custos de armazenamento, produção e transporte utilizando o espaço correto de estocagem. (BALLOU, 2010)

O mesmo autor afirma ainda, que administrar uma empresa com estoque zero não seria prático e nem econômico, pois a demanda na maioria das vezes não é prevista com exatidão, chegando a originar um diferencial entre ela e a oferta, a produção teria que ser instantânea e o transporte totalmente confiável com prazo zero para a entrega, causando um custo alto de reposição.

Dias (2010), Gonsalves (2010) e Ballou (2010) declaram que ao falar em armazenagem deve-se levar em consideração a movimentação de estoque uma vez que uma depende da outra e viceversa.

Não existe, ou pelo menos, não é cômodo utilizar-se de estruturas ou formas préfabricadas quanto ao sistema de estocagem de cargas, pois sua eficiência depende das condições do local e da organização, além de fatores indiretos que podem transformar drasticamente o sistema escolhido. (DIAS, 2010)

Finalidades da Estocagem 
Ballou (2010) expõe quatro motivações essenciais para que se utilize um espaço adequado à estocagem dentre os quais o primeiro corresponde à redução dos gastos de transporte e produção, no aprimoramento da coordenação de oferta e demanda, assessorando no processo de produção a fim de colaborar no processo de distribuição.

Bowersox e Closs (2010) citam varias vantagens de se armazenar dentre as quais ressalta a vantagem econômica, que segundo eles não são difíceis de quantificar, pois apenas uma análise de trade-off entre os custos logísticos.

Outra vantagem apresentada pelos autores supracitados é a de serviço que não está diretamente relacionado com a redução de custos, pelo contrário as vantagens estão associadas ao tempo e localização.

Bawersox e Closs (2010) compreendem que o estoque não só é uma variável bastante significativa como também essencial, onde um mau gerenciamento poderia ocasionar fortes gastos, tendo em vista que o estoque corresponde à parte da organização que possui maior valor de capital retido.

Entre outras finalidades e vantagens citadas, Gonçalves (2010) diz existir quatro pontos necessários para uma armazenagem eficaz. São:

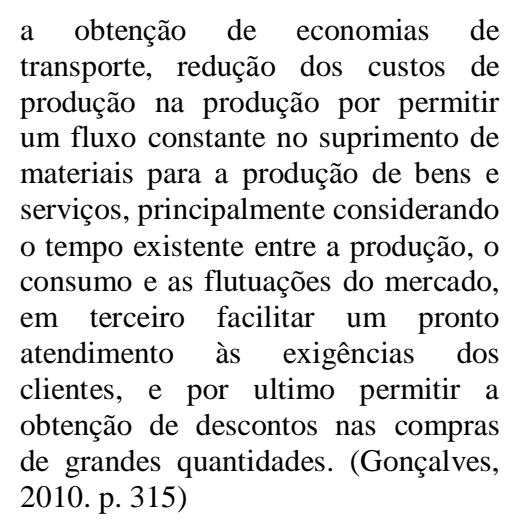

Formas de Estocagem
Para Ballou (2010) e Bowersox e Closs (2010) a decisão de manter estoques depende de vários acordos jurídicos e financeiros. Devendo ser levantando projetos pelo profissional de logística a fim de fazer uma boa escolha de como e onde estocar, sendo estas variedades infinitas, porém quatro delas é básica: a propriedade, aluguel, arrendamento e estocagem em trânsito.

- Propriedade de espaço - É uma das formas mais utilizadas pelas organizações, empresas ou prestadores de serviços, manter seu próprio espaço físico e equipamentos para a estocagem de infinitos materiais, sendo mais econômico, não há custos com aluguel, o espaço geralmente é maior para movimentação de materiais, facilita em casos dos produtos que requer mão de obra especializada como medicamentos, explorar de benefícios da propriedade privada, onde pode também havendo necessidade inserir uma sede de vendas, departamento de transportes ou de compras.

- Aluguel de espaço - ocorre quando empresas optam por terceirizar o espaço de estocagem e nas muitas vezes também a mão de obra, transportes e a própria venda, criando uma independência com os proprietários de uma frota privada de transportes.

- Arredamento de espaço - são espaços provenientes de arrendamentos de armazéns públicos, onde as empresas privadas alugam espaço por um prazo muito longo e diante da descontinuidade das atividades ou mesmo por não conseguir usar todo o espaço, arrendam parte desse espaço para outras empresas, A vantagem para quem arrenda é diminuir custos e flexibilidade de localização.

- Estocagem em Trânsito - Se dá quando os produtos são mantidos no transporte, não são estocados em armazéns por tratarem de produtos sazonais ou remessa para longa distância. 
Segundo Gonçalves (2010), para que aconteça a otimização do espaço de um almoxarifado deve-se levar em conta três critérios de muito valor, onde o primeiro é que o local deve se acessível, e segundo os equipamentos de movimentação e estocagem e em terceiro os tipos de embalagens utilizadas.

Ainda segundo o mesmo autor a acessibilidade terá de ser construída objetivando um fácil acesso ao material desejado e tem dois focos essenciais. O primeiro diz respeito a como o sistema de localização está projetado e estruturado e por fim como planejamento de um posicionamento adequado do material. Em suma a acessibilidade é a possibilidade de encontrar o material almejado no menor tempo e com menor custo possível.

Além deste sistema de localização é necessário examinar a flexibilidade deste sistema, ou seja, de que maneira pode-se retirar um material sem que para isso haja a necessidade de deslocamento de outros itens. (GONÇALVES, 2010)

\section{Tipos de Armazéns e Estocagens}

Ballou (2010) define os tipos de instalações de armazéns privados como sendo o preferencial entre as organizações cujas funções dos projetos atende as necessidades especificas. Para atender uma grande demanda os armazéns públicos têm especializações amplas a fim de atender todo o público, com maior padronização na utilização do espaço e equipamentos diferenciando-se dos privados até mesmo por serem muitos deles locais reformados. Estão classificados em:

1. Armazéns de commodities - São especializados em estocagem de materiais de grandes estragos como fumo, cereais, madeira e etc.
2. Armazéns de volumes de granéis - Estão voltados para estocagem de materiais como petróleo, produtos químicos, ácidos entre outros, podendo haver fracionamento de volumes $\mathrm{e}$ combinações de produtos.

3. Armazéns de temperatura controlada Estocagem de produtos perecíveis que requer refrigeração controlada, como fruta, laticínios e demais materiais que necessitam desse cuidado.

4. Armazéns de produtos residenciais Utilizados por empresas fabricantes e revendedoras de móveis, porém empresas de mudanças residenciais também fazem uso desse tipo de armazém.

5. Armazéns gerais de mercadorias - È um dos armazéns mais usado por receberem uma variável muito grande de produtos que não requer cuidados especiais como os já citados, as instalações não pede especializações.

6. Mini armazéns - são armazéns de porte pequeno, sua utilização provém de um local que proporciona fácil acesso cuja segurança é deficiente.

Os armazéns de produtos gerais comumente pode na prática juntar estoque de alimentícios ou mesmo manter uma estocagem de refrigeração. Então os armazéns não estão limitados as suas classificações podem ser alterados de acordo com negociações ou necessidades. (BALLOU, 2010)

Já Lambert e Stock (1993) apud Gonçalves (2010) dividem em três blocos os tipos de armazenagens sendo o primeiro de apoio à manufatura, direcionado a guardar matérias-primas e insumos advindos de vários fornecedores para o abastecimento da fábrica, armazéns compostos que além de estocar matéria-prima e insumo armazena produtos acabados destinados aos clientes e por fim o de consolidação tendo como objetivo a expedição dos produtos aos clientes com cargas combinadas 
para atender as necessidades específicas de cada cliente.

Enquanto para Bowersox e Closs (2010) os tipos de estocagens podem ser classificados como estoque de produção, atacado ou varejo, os quais estão descriminados abaixo.

- Produção: o processo de estocagem de produção difere dos demais tipos, por possuir basicamente três tipos de estocagens sendo a primeira de matéria-prima, a segunda de materiais semiacabados e materiais acabados incorrendo em um risco de investimento ou obsolescência à logo prazo.

- Atacado: quanto ao risco descrito no ponto anterior, este é menor, porém, com um maior intervalo de tempo. Outra desvantagem esta na composição do composto de produtos uma vez que este ao se aproximar do mix do varejista e mais quando em períodos sazonais estes são obrigados a armazenar um numero maior de materiais.

- Varejo: diferente dos anteriores para os varejistas o estoque está relacionado à compra e venda do produto e os riscos envolvidos são mais banais, podendo ser considerados abundantes, mas não tão profundos.

\section{Ramificações do Sistema de Estocagem}

O sistema de estoque se divide em duas funções: estocagem e manuseio de materiais. Funções estas que estão entrelaçadas na movimentação dos produtos devidamente armazenados e na distribuição dos materiais. O acúmulo dos produtos ocorridos com o passar do tempo é denominado estocagem, onde são escolhidos diferentes locais e diferentes períodos, variando de acordo com o objetivo da mesma. O manuseio dos materiais envolve toda a atividade de carga e descarga, movimentação dos produtos e separação dos pedidos. (BALLOU, 2010)
Segundo o autor supracitado as funções de estocagem são programadas a partir de quatro funções primárias: manutenção, consolidação, fracionamento e combinação de estoque.

- Manutenção - A finalidade de estocagem com as devidas instalações e especificações é garantir a proteção e a manutenção ordenada dos materiais. A configuração e o layout de estocagem pode ser à longo prazo, de uso comum, ou mesmo temporário determinando a acumulação de quantidades eficientes de produtos acabados, semiacabados e matérias-primas.

- Consolidação - Os custos obtidos com transportes e/ou desdobramentos por grupos recebe influência na utilização das instalações de armazenagem podendo diferenciar $\mathrm{o}$ frete, proporcionando uma consolidação compensatória destes custos com armazenamento intermediário.

- Fracionamento de volumes - Trata-se da redução de volumes de materiais para armazenagem, onde se dá a remoção de materiais para o armazém e a partir dali redistribui em quantidades menores, sendo chamados de armazém de distribuição ou terminais, tornando os custos de transportes menores proporcionando aos clientes fazer seus pedidos em lotes econômicos, uma vez que estão localizados próximo aos clientes.

- Combinação de estoque - A aquisição de materiais de diversos fabricantes, a fim de compor uma linha de produtos variada, tende a sentir necessidade de um estabelecimento cujo armazém seja um ponto de combinação destes materiais, proporcionando economia em transportes. Este ponto de combinação permite uma maior variabilidade na linha de produtos em um único estoque, sempre com o layout de acordo com os pedidos para os clientes.

Quando as técnicas de armazenamento são necessárias observar as recomendações do fabricante, pois, em alguns casos os materiais 
precisam de cuidados específicos, dentre as quais pode-se citar materiais que precisam de temperatura diferenciada, com empilhamento máximo entre outros. (GONÇALVES, 2010)

\section{Ramificações de Movimentação dos Materiais}

Para Ballou (2010) estas ramificações estão representadas por três atividades principais: carga e descarga; movimento para e da estocagem; e atendimento dos pedidos.

- Carga e descarga - É a primeira e a última das atividades dentro do manuseio dos materiais. Chegada do produto, descarregamento feito por equipamentos de transportes adequados, podendo ser realizados em uma única vez ou em dois processos separados, tendo necessidade de uso de equipamentos especiais, com guindastes para navios, descarregadores mecânicos para vagões. Logo em seguida ao desembarque são contadas, inspecionadas e classificadas para serem removidas ao armazém. A carga é a atividade oposta à descarga, antecede ao embarque dos materiais, uma verificação final do conteúdo do pedido, onde exige esforços adicionais para a prevenção de danos com a amarração e o reforço das embalagens.

- Movimentação para e da estocagem - Dáse aos variados movimentos dos materiais desde seu fabricante até o cliente. Iniciando esta movimentação do ponto de descarga para o estoque, do estoque para a área de separação de pedidos, e, em seguida, seu embarque, formando ligação e conexão na rede do sistema de estocagem. Disponibilizando dos diversos tipos de equipamentos para manuseio de materiais, entre eles, carrinhos manuais de carga automatizados e computadorizados de empilhamento e localização de mercadorias estocadas.

- Atendimento dos pedidos - É a seleção de materiais de acordo com pedidos feitos pelo cliente, a saída ordenada de materiais em quantidades fracionadas, exigindo muita mão de obra com custos maiores do que outras atividades.

Alguns critérios devem ser analisados para que se possa obter uma redução dos custos de movimentação dos materiais e maximizar a acessibilidade, são estes: volume de armazenamento; peso do material; acondicionamento e embalagem; frequência de movimentação; rotatividade dos estoques; valor do material; critério de fornecimento e etc. (GONÇALVES, 2010)

\section{MOVIMENTAÇÃO DE MATERIAIS}

Segundo Ballou (2010) o manuseio de materiais está ligado diretamente ao tipo de decisão tomada quanto à estocagem desses materiais, se optarem por armazém controlado por empresas privadas, seu objetivo principal é a excelência na operação de manuseio de materiais. $\mathrm{Na}$ grande maioria é uma atividade que traz grandes custos, variando de acordo com o tempo do ciclo de pedido dos clientes e sobre o serviço ao cliente.

Sendo assim o objetivo da movimentação de materiais é a busca pela eficiência dessa atividade reduzindo custos à medida que aumenta o espaço utilizado. E esse aperfeiçoamento se dá através da prática desenvolvida ao longo de quatro linhas: a unificação da carga, o layout do espaço, a escolha do equipamento de estocagem e a escolha do equipamento de movimentação. (BALLOU, 2010)

$\mathrm{O}$ uso de carregamentos padronizados tem por finalidade além da redução de custos a facilitação do manejo e transporte dos materiais. Estes permitem a redução dos custos de mão de obra, maior agilidade na movimentação, melhor aplicabilidade dos equipamentos de movimentação 
e transporte e melhor aproveitamento do espaço cúbico. (GONÇALVES, 2010)

\section{Unitização da Carga}

Levando em consideração de que a economia está ligada diretamente ao tamanho da carga manuseada, pode-se dizer que quanto maior o numero de materiais movimentados, menos viagens serão necessárias para atender as necessidades de estocagem. Reduz o tempo de circulação do produto e o tempo do uso dos equipamentos de manuseio de materiais exposto ao uso. (BALLOU, 2010)

Para Ballou (2010) a eficiência pode ser melhorada no fechamento de carga como número de volumes menores numa única carga e consequentemente o manuseio da carga fechada. A esta operação dá-se o nome de unificação da carga feita por meio de paletização e conteinerização.

\section{Paletização}

Um palete é uma estrutura de madeira ou material reforçado utilizada no carregamento de materiais facilitando o transporte e estocagem, é a uma base. É uma ferramenta de custo agregado ao sistema de manuseio de matérias que com sua utilização esses custos vão sendo justificado. Proporciona mais eficácia por ser manuseada por equipamentos mecânicos, facilita a unificação da carga devido o aumento do peso e redução do volume, aumenta a utilização do espaço por ser estocados empilhados, possibilitando estoques mais altos. (DIAS, 2010; BALLOU, 2010; BOWERSOX e CLOSS, 2010)

Dentre dos diversos fatores que necessitam ser considerados para se escolher um palete destacam-se, peso, tamanho, capacidade de carga, umidade etc. (DIAS, 2012)
Todos os autores estudados consideram que o tamanho do palete varia de acordo com o país, no Brasil o mais utilizado é 1200 por $1000 \mathrm{~mm}$, levando em consideração a forma, peso e vulnerabilidade dos produtos e a capacidade do equipamento de manuseio. $\mathrm{O}$ carregamento do palete deve considerar também a distribuição e a estabilidade da carga.

Gonçalves (2010) destaca três tipos de paletes mais utilizados, o palete de face única, de dupla face e o padrão de 1,20m x 1,00m.

Para Dias (2012) os paletes podem ser classificados como: de duas entradas de quatro entradas, de uma face ou de duas faces cada qual com sua vantagem para determinados tipos de situações empregados.

\section{Conteinerização}

Contêiner são caixas grandes para estocagem e transportes de materiais. É melhor opção para unificação da carga. A prova d'agua e de arrombamentos torna desnecessária a armazenagem comum dos materiais. Pode ficar expostos em locais abertos onde equipamentos padrão de manuseio possibilita o movimento do contêiner. (BALLOU, 2010)

Ballou (2010) explica ainda não existe padrão quanto ao tamanho do contêiner devido seu uso generalizado e são usados raramente.

\section{Layout do Espaço}

Os materiais estocados nos armazéns devem está organizados de forma padronizada que proporcione agilidade no manuseio desses materiais quanto à separação de pedidos, por afetar diretamente nos custos gerais de manuseio, já que busca a redução de despesas e a utilização de 
espaço do armazém. (BALLOU, 2010; BOWERSOX E CLOSS, 2010)

Bowersox e Closs (2010) apontam ainda para dificuldade em generalizar algum tipo de layout uma vez que este deve atender à algumas exigências, na qual a primeira é que deve ser adequado ao produto.

Seguindo a mesma linha de raciocínio dos autores citados acima Gonçalves (2010) destaca que além do espaço de armazenagem ter de ser propício ao produto trabalhado deve-se atentar para três fatores de bastante influência.

São estes: I - eficácia na
utilização dos equipamentos de
movimentação e transporte, II -
utilização de pessoal qualificado e
treinado para realizar as operações
internas, III - maximização do
uso do espaço cúbico disponível.
(GONÇALVES, 2010. P. 314)

\section{Layout para Estocagem}

Quanto ao percentual de giro dos materiais, a principal preocupação é com a estocagem. As prateleiras podem ser largas e fundas, e o empilhamento pode ser alto quanto o permitido pela altura interna ou estabilidade da carga. Os corredores podem ser estreitos de forma que priorize a movimentação de estoques para dentro e para fora das áreas de permanência. (BALLOU, 2010)

Tratando de materiais de giro rápido é necessária a realização de mudanças no layout para que os custos de manuseio continuem razoáveis, devendo os corredores serem mais largos e o empilhamento mais baixo. (BALLOU, 2010)

\section{Layout para Separação dos Pedidos}

A separação de pedidos requer um maior gasto de tempo do que na estocagem. Uma layoutização para a estocagem dos pedidos é necessário uma modificação referente a altura do empilhamento, localização dos produtos; necessitando de fracionamento de volumes se o giro do produto é alto. (BALLOU, 2010)

O objetivo é diminuir o tempo de movimentação evitando longa distância no próprio armazém para atender aos pedidos. Utilizando o sistema modificado de área os armazéns são projetados para atender as necessidades de estocagem e da total ocupação do espaço, enquanto outros teriam projeção de acordo com a necessidade de separação de pedido e do tempo mínimo de movimentação para o atendimento dos pedidos. (BALLOU, 2010)

Para Dias (2012) existem dois tipos de estocagem, o primeiro é o de estocagem fixa, onde se determina um espaço direcionado apenas para um produto ou material estipulado, correndo o risco de desperdício de áreas de estocagem, pois, com uma intensa entrada e saída de produtos pode acontecer de se faltar material em alguns locais e em outros ter em excesso.

No segundo só existe local fixo para materiais especiais, todo o restante ocupará espaços disponíveis no armazém o que dificulta o controle. (DIAS, 2012)

\section{Escolha do Equipamento de Estocagem}

A estocagem e o movimento de materiais são atividades que andam juntam, onde a estocagem é um tempo de parada dos materiais do armazém (BALLOU, 2010).

$$
\text { Para Ballou (2010) o principal }
$$
equipamento da estocagem é a prateleira, cuja divisão deve atender a ampla variedade de itens expostas em pequenas quantidades, sendo elas de metal ou madeira. Auxilia no empilhamento de cargas com grande eficácia, promovendo o empilhamento do chão ao teto, auxilia no giro dos estoques. Outros acessórios disponíveis são as caixas de repartições, contentores horizontais e 
verticais, escaninhos e gavetas; todos eles auxiliando de forma organizada e ordenada no manuseio de materiais.

\section{Tipos de movimentação}

A uma grande variedade de equipamentos de movimentação dos produtos no armazém, disponíveis tanto para carga e descarga e separação de pedidos. Esses equipamentos se distinguem de acordo com a necessidade existente na estocagem para a movimentação dentro do armazém. São três as categorias abrangentes e bem caracterizadas de tais equipamentos: manual, misto (com o auxílio de energia) e totalmente mecanizado; podendo encontrar em um só armazém as três variações em uso. (BALLOU, 2010)

Uma escolha eficaz dos equipamentos de movimentação e armazenagem, esta relacionado à movimentação e transporte de materiais, tendo como princípios à redução de custos, aumento da produtividade, da capacidade de utilização do almoxarifado, melhora a segurança reduzindo o número de acidentes e até mesmo a fadiga dos trabalhadores e por fim melhora a movimentação dos materiais em si. (GONÇALVES, 2010)

\section{Equipamento Manual}

São exemplos de equipamento manual os carrinhos de duas rodas e as paleteiras de quatros rodas, que viabilizam vantagens mecânicas no manuseio dos produtos e de baixo custo. Há uma variação de modelos adaptados para a movimentação de produtos especiais (tapetes, móveis, entre outros). Em armazém com estocagem com mix de produtos que requer flexibilidade e dinamismo, esses equipamentos são ideais. Sendo limitado o seu uso a força física do operador. (BALLOU, 2010; GONÇALVES, 2010)

\section{Equipamentos Mistos}

São exemplos de equipamento mistos os guindastes, truques industriais, elevadores e guinchos; esses equipamentos têm por características a rapidez e a eficácia da movimentação de materiais e a redução de hora trabalhada. Outro exemplo também é o "cavalo de batalha" usado na indústria e na empilhadeira mecânica em seus diversos modelos. (BALLOU, 2010)

Para Gonçalves (2010. P. 322) a eficiência de um sistema de movimentação e transporte depende da observância de algumas regras denominadas de leis da movimentação de materiais, entre elas: lei da obediência do fluxo das operações; lei da mínima distância; leia da manipulação mínima; lei da máxima utilização do espaço disponível; lei da padronização; lei da flexibilidade; lei da máxima utilização da gravidade; lei do menor custo total.

$\mathrm{O}$ uso da empilhadeira, palete $\mathrm{e}$ prateleiras do armazém compõe um sistema que todo mundo conhece e utiliza por ter um custo baixo, sendo usado em uma área de armazenagem de cargas elevadas. (BALLOU, 2010)

\section{Equipamentos Mecanizados}

São equipamentos que requerem manuseios automáticos que são controlados por computadores, códigos de barra e tecnologia de escaneamento. É o equipamento que mais abrange o uso da tecnologia diante de outras alternativas. (BALLOU, 2010)

\section{METODOLOGIA}

Trata-se de uma pesquisa exploratória, descritiva e de campo, com abordagem qualitativa. Segundo Oliveira (2007) pesquisa é um estudo da literatura referente ao tema abordado, para refletir e 
analisar a realidade utilizando método de observação direta intensiva com o uso de um questionário de entrevista para realização de uma análise dos dados coletados.

A pesquisa qualitativa jamais poderá ser quantificada, sendo um mundo de conhecimentos das ações humanas, possibilitando entender e explicar a dinâmica das relações sociais, trabalhando a vivência, com a experiência, com as atitudes, valores e hábitos de forma objetiva (MINAYO, 2005).

Na concepção de Rudio (2003) o estudo descritivo busca captar informações reais a fim de descrever e interpretar o que realmente acontece entre o ambiente, o pesquisador e os sujeitos.

Para o estudo de caso definido por Stake (1995, p. xi) apud Gil (2009, p. 6) “o estudo da particularidade e da complexidade de um simples caso", foram utilizados quatro parâmetros, dos quais o primeiro foi os dados gerais da empresa e do entrevistado, segundo a infraestrutura do local em terceiro as técnicas, materiais e equipamentos usados na movimentação e armazenagem de estoque, por fim o sistema de tecnologia empregado.

O estudo foi desenvolvido na empresa CEALTA, uma empresa voltada para de distribuição de produtos atacado.

A escolha do cenário deu-se em virtude dessa instituição ser uma empresa consagrada na região do cariri sendo referência em distribuição de produtos no atacado e por se mostrar disponível a receber estudantes da graduação, facilitando $\mathrm{o}$ acesso dos autores para a realização do estudo.

O sujeito da pesquisa foi o gestor de logística da empresa supracitada, pois este é o responsável pela gestão da armazenagem de matérias nos setores do galpão. Os critérios de inclusão seria o profissional de gestão em logística que concorda em participar do estudo, independente do tempo de atuação na empresa. Foram excluídos gestores de outros departamentos da empresa, tendo em vista que o sujeito entrevistado contemplou todos os nossos questionamentos.

Durante a entrevista o sujeito foi informado sobre os objetivos da pesquisa. Foram esclarecidos sobre seu caráter voluntário conforme leitura do Termo de Compromisso Livre e Esclarecido.

A coleta de dados foi realizada no dia vinte de outubro de 2014. Os dados foram coletados através de uma entrevista semiestruturada. Segundo Chizzotti (2005) nesse tipo de entrevista o entrevistado terá a possibilidade de discorrer sobre o tema proposto sem respostas ou condições previamente fixadas pelo entrevistador, sendo desta forma um excelente instrumento para aprofundamento qualitativo de investigação.

Segundo Minayo (2005) a entrevista serve para buscar e coletar dados em uma pesquisa de campo, a partir das falas dos entrevistados, onde se deve de maneira geral atingir um objetivo. Sendo este adequado às especificidades de cada grupo buscando entender o que o entrevistado quer passar com a fala e obter dados a respeito do estudo. Define também a entrevista semiestruturada como sendo uma articulação entre a entrevista estruturada e a não-estruturada, na qual o entrevistador pode abordar outros pontos de interesse no decorrer da entrevista, havendo maior flexibilidade e consequente enriquecimento da investigação.

Foi utilizada uma filmadora digital para gravação da entrevista como forma de preserva sua fidedignidade e um pen drive para o armazenamento do conteúdo após a transcrição e digitação da fala do sujeito entrevistado.

A análise dos dados foi realizada em novembro de 2014. Os discursos foram transcritos na íntegra e agrupados em categorias temáticas. Depois da realização da categorização dos dados, 
estes foram analisados seguindo as etapas propostas por Minayo (2005)

Primeiro foi realizada um análise prévia, organizando os dados a partir de uma leitura flutuante, isto é, realizando um contato exaustivo com o material, para haver uma impregnação do conteúdo. Vencida esta etapa houve a exploração do material para haver uma compreensão do tema. Por fim, foram interpretadas as falas do sujeito de modo a aproximar o entendimento da equipe de graduandos de administração no sistema de movimentação e armazenamento de materiais no setor atacadista.

\section{ANÁLISE E DISCUSSÃO DOS RESULTADOS}

O estudo de caso foi estruturado para apresentar os dados na seguinte ordem: primeiro os dados gerais da empresa, infraestrutura do armazém, técnicas e equipamentos para movimentação e armazenagem de materiais e por fim o sistema de gerenciamento de cadeia utilizado.

O objeto da pesquisa foi a empresa de Comércio de Produtos Alimentares L.T.D.A., nome Fantasia CEALTA, propriedade do senhor Antônio Jatai Pedrosa, localizada em Juazeiro do Norte CE, Campo Alegre, Rua Paizinho Sabiá 1395.

A empresa tem 35 anos de atividade econômica no ramo de distribuição de Estivas, Cereais e Produtos agropecuários. O entrevistado foi o Igo Raimundo Firmino Maia Chefe de Logística que tem 18 anos de experiência sendo um ano e quatro meses só nesta empresa.

O armazém estudado é privado, ponto este que já traz em se uma redução de despesas de aluguel ou arrendamento. Pelo que sua estrutura e tipo de produto o local é classificado como armazém geral de material. A empresa é separada em três grandes áreas. Esta forma de estocagem permite ao proprietário um maior controle e flexibilidade para adaptar o espaço as suas necessidades.

A primeira área é de recebimento, conferência e expedição de materiais, sendo esta separada em nove boxes e um departamento de transportes. Todo o processo tem inicio no setor de compras, onde a nota fiscal dos produtos recebidos é armazenada no momento de conferência dos produtos, pois é emitida apenas uma nota com o nome e a marca do produto, técnica esta aplicada para reduzir os erros de recebimentos de mercadoria errada ou até mesmo de produtos incompletos.

A segunda área é a de movimentação e estocagem que é dividida em nove blocos de prédios de cinco andares, explicou ainda o entrevistado que a parte inferior do prédio é o Picking onde os produtos são segmentados para facilitar a separação dos pedidos e as partes superiores são denominadas de pulmão e são usadas para o empilhamento das cargas unitizadas e destinado à reposição de produtos dos Picking's.

O chefe de logística também declarou que usa uma técnica de combinação de materiais, esta por sua vez, reduz o tempo de separação dos pedidos, bem como, os possíveis erros com produtos similares. Expôs ainda que todo o restante dos andares é denominado de pulmão.

No pulmão, mais especificamente no espelho, local da carga que fica à vista nas estruturas, de todas as cargas unitizadas é fixado um papel contendo informações do tipo: data de validade e lote de compra, servindo para controlar e diminuir o numero de mercadorias prestes a vencer, processo realizado apenas de forma manual, deficiência esta que logo será suprida com um novo sistema de gestão integrada, ressalta o entrevistado.

São utilizados apenas três equipamentos pela empresa são estes: empilhadeira: como o próprio nome já diz sua utilidade se limita a alocar 
os blocos unificados de produtos nos prédios (estrutura porta paletes), paleteira elevadora: capacidade de elevar um bloco de produtos com peso de aproximadamente $1000 \mathrm{~kg}$ e transporta-los facilmente entre as ruas (corredores), paleteira manual: utilizada para transportar produtos sobre os paletes de maneira manual para locais mais próximos ou até mesmo para a carga ou descarga.

Os paletes são todos padronizados do tipo de face única de quatro entradas com dimensões de 1, 20 metro por 1, 00 .

$\mathrm{O}$ espaço entre as estruturas porta-paletes estão organizadas de forma a agilizar todo o processo de estocagem e separação de pedidos possuindo tamanho superior ao da própria estrutura.

Sabendo do perigo e da facilidade de possíveis contaminações dos produtos agrícolas e perfumaria com os alimentos, o primeiro é distante dos outros dois, localizado na terceira parte seção do armazém onde parte do espaço é usado para separação, e os últimos são separados por uma coluna de produtos descartáveis pra o isolamento entre eles.

A terceira área do armazém como antes descrito também é parte do processo de separação dos pedidos onde os materiais aguardam o esvaziamento dos boxes de recebimento e despacho para prosseguir rumo ao cliente.

Ao chegar do box para expedição é refeito uma conferencia cega afim de identificar possíveis falhas e corrigi-las, só então o produto é carregado em caminhões e segue à destino dos clientes.

O sistema de controle utilizado pela empresa é o Win Thor WMS, ferramenta eficaz para o gerenciamento da cadeia de logística, permitindo total controle sobre todos os materiais armazenados. Este sistema tem por finalidade acelerar o processo de separação e despacho dos produtos, maximizar a utilização do layout e o controle da rotação dos estoques. (PC SISTEMAS, 2014)

Segundo Gonçalves (2010) a informática é um elemento importantíssimo de apoio e manutenção dos registros e informações necessários aos diversos órgãos da empresa, envolvendo as várias etapas do fluxo de suprimento de bens, tanto destinados à produção quanto ao abastecimento do mercado consumidor.

As principais melhorias obtidas com a implantação deste sistema são:

- Redução de turno e ganho na produtividade no $\mathrm{CD}$;

- Aumento em até $60 \%$ da sua produtividade com trabalhos direcionados;

- Eficiência em Logística com redução de inversão de produtos com o uso de checkout's ou equipamentos de rádio frequência;

- Melhor alocação dos produtos na armazenagem;

- WMS permite a geração de dados para o cálculo de indicadores de desempenho e métricas parametrizáveis;

- Melhor dimensionamento de Picking's;

- Controle do FEFO (Primeiro a vencer primeiro a sair) e FIFO (primeiro a entrar primeiro a sair).

- Aumento do nível de qualidade dos serviços logísticos;

- Redução de custos com mão de obra no CD (Eliminação de retrabalhos);

- Aumento do nível de acuracidade (Confiabilidade) dos estoques. (PC SISTEMAS, 2014)

A importância da utilização deste sistema de controle é evidenciada pela sua participação em 
43\% dos Atacadistas Distribuidores segundo o Ranking ABAD (PC SISTEMAS, 2014).

A empresa pretende ainda implantar o sistema Win Thor ERP que é uma ferramenta integrada de gestão que torna ágil a distribuição dos materiais e "facilita o controle e a gestão de todos os processos do negócio do atacado distribuidor." (PC SISTEMAS, 2014)

\section{CONCLUSÃO}

Após a análise da pesquisa bibliográfica e dos dados fornecidos pela empresa pode-se constatar uma série de vantagens advindas da aplicação das técnicas e materiais específicos para movimentação e armazenagem de materiais.

Outro ponto percebido foi que a empresa possui capacidade de inserir uma gama de sistemas aplicáveis para melhorar ainda mais seu estabelecimento, bem como, para reduzir seus custos de armazenagem e apresentar vantagens competitivas para os clientes.

A primeira vantagem identificada é o fato de que o armazém é privado e só este fator configura em uma redução dos custos com arrendamento ou mesmo aluguel, permite ainda ao proprietário uma modificação do layout de espaço que melhor se adeque aos seus produtos.

Outra vantagem constatada é a verificação "cega" adequada para um correto recebimento e expedição de produtos, isso permite uma segurança na quantidade de produtos estocados com a plena certeza dos materiais estocados.

A organização do espaço em geral aliado a um sistema WMS de gestão de materiais permite um processo mais ágil de armazenagem movimentação e separação de pedidos utilizando-se da técnica PEPS (primeiro a entrar é o primeiro a sair), garantido um nível de avaria e de vencimento de produtos próximos à zero.
Por seus largos corredores e equipamentos de seguranças e correto uso dos equipamentos de movimentação e armazenagem fez com que durante um ano e quatro meses, ou seja, durante todo o período da implantação do sistema zerou-se o numero de acidentes de trabalho.

Todas as vantagens unidas fazem com que a empresa se destaque no mercado atacadista atual pela velocidade e precisão na entrega dos seus produtos e utiliza-se deste recurso como vantagem competitiva diante de seus concorrentes, o que oportuniza aos seus clientes receberem seus produtos na hora desejada, da maneira desejada com a qualidade desejada.

Recomenda-se que sejam feitas pesquisas nas estruturas de custo dos produtos da empresa de modo a identificar de maneira mais precisa e quantificável as reduções percebidas de forma a oferecer ao gestor geral condições de utilizar estas reduções pra uma possível melhoria nos preços ou mesmo como um diferencial competitivo.

Aconselha-se ainda verificar a possibilidade de se implantar um sistema de qualidade total dentro da empresa de maneira que possibilite a mesma a se manter sempre a frente de seus concorrentes.

\section{REFERÊNCIAS}

BALLOU, Ronald H. Gerenciamento de cadeia de suprimentos/logística empresarial. $5^{\mathrm{a}}$ ed. Porto Alegre: Bookman, 2010.

BOWERSOX, Donald J.; CLOSS, David J. Logística empresarial: o processo de integração de cadeia de suprimento. $1^{\text {a }}$ ed. São Paulo: Atlas, 2010.

CHIZZOTTI, A. Pesquisa qualitativa em ciências humanas e sociais. Petrópolis, Rio de Janeiro: Vozes, 2006. p 20.

DIAS, Marco Aurélio P. Administração de materiais: princípios, conceitos e gestão. $5^{\mathrm{a}}$ ed. São Paulo: Atlas, 2012. 
DIAS, Marco Aurélio P. Administração de materiais: uma abordagem logística. $5^{\mathrm{a}}$ ed. São Paulo: Atlas, 2010.

GIL, Antônio Carlos. Estudo de caso. São Paulo: Atlas, 2009.

GONÇALVES, Paulo Sergio. Administração de materiais. $3^{\mathrm{a}}$ ed. Rio de Janeiro: Elsevier, 2010.

MINAYO MCS. Pesquisa social: Teoria método e criatividade. $24^{\mathrm{a}}$ ed. Petrópolis: Vozes, p.45-47, 2005.

OLIVEIRA, M. M. de. Como Fazer uma pesquisa qualitativa. $1^{\mathrm{a}}$ ed. Petrópolis, RJ: Vozes, 2007. p. 23-25.

PC SISTEMAS. Gestão ágil, fácil. Inteligente. Disponível em: <http://www.pcsist.com.br/distribuidor.php>. Acesso em: 18 Out. 2014.

PC SISTEMAS. Know How. Disponível em: <http://www.pcsist.com.br/clientes.php>. Acessado em: 18 Out. 2014.

PC SISTEMAS. Organização e controle absoluto. Disponível em: <http://www.pcsist.com.br/modulo_wms.php〉. Acessado em: 18 Out. 2014.

RUNIO, F. V. Introdução ao projeto de pesquisa científica. 32a ed. Petrópolis: Vozes, 2004. p. 23. 